\title{
Lupulone triggers p38 MAPK-controlled activation of p53 and of the TRAIL receptor apoptotic pathway in human colon cancer-derived metastatic cells
}

\author{
VIRGINIE LAMY ${ }^{1,2}$, SOUAD BOUSSEROUEL ${ }^{1,2}$, FRANCINE GOSSÉ ${ }^{1,2}$, \\ CAROLE MINKER ${ }^{3}$, ANNELISE LOBSTEIN ${ }^{3}$ and FRANCIS RAUL ${ }^{1,2}$ \\ ${ }^{1}$ Unit of Physiopathology and Translational Research EA 4438, University of Strasbourg, Faculty of Medicine, Strasbourg; \\ ${ }^{2}$ IRCAD - EITS, Strasbourg; ${ }^{3}$ CNRS UMR7081, University of Strasbourg, Faculty of Pharmacy, Illkirch, France
}

Received January 17, 2011; Accepted March 10, 2011

DOI: $10.3892 /$ or.2011.1273

\begin{abstract}
We previously reported that the chemopreventive agent lupulone induces apoptosis through activation of the extrinsic pathway via TRAIL DR4/DR5 death receptors overcoming SW620 cell resistance to TRAIL. However, the underlying molecular mechanisms remain unknown. Since the mitogen-activated protein kinases (MAPKs), Jun N-terminal kinase (JNK), extracellular signal-regulated kinase (ERK) and p38 control fundamental cellular processes such as apoptosis, we determined the role of these MAPKs in lupulone-triggered apoptosis. We analyzed the effects of JNK, ERK and p38 MAPK inhibitors on lupulone-induced apoptosis by flow cytometry using specific antibodies and real-time RT-PCR. Our data showed that among the MAPKs, only p38 played a major role in lupulone-triggered apoptosis. In contrast to JNK and ERK inhibition, the specific inactivation of p38 inhibited the lupulone-triggered up-regulation of p53 and TRAIL-death receptor DR4/DR5 expression, and prevented DNA fragmentation. Lupulone treatment enhanced the expression of the anti-apoptotic Mcl-1 protein by $60 \%$ favoring the preservation of mitochondrial integrity. The inactivation of p38 initiated a 50\% reduction in $\mathrm{Mcl}-1, \mathrm{Bcl}-2$ and Bax expression without changing the $\mathrm{Mcl}-1 / \mathrm{Bax}$ ratio suggesting that $\mathrm{p} 38$ was not involved in the protective effect of lupulone on mitochondria. Our data support the view that the lupulone-triggered enhanced expression of p38 plays a major role in the activation of p53 and of the TRAIL-death receptor apoptotic pathway in SW620 human colon cancer-derived metastatic cells.
\end{abstract}

\section{Introduction}

Family members of the mitogen-activated protein kinases (MAPK) regulate and control fundamental cellular processes

Correspondence to: Dr F. Raul, Laboratory of Nutritional Cancer Prevention, IRCAD, 1 Place de l'hôpital, 67091 Strasbourg-Cedex, France

E-mail: francis.raul@ircad.u-strasbg.fr

Key words: SW620 cells, apoptosis, TRAIL, p53, Mcl-1 such as growth, proliferation, differentiation, migration or/and apoptosis. Distinct groups of MAPKs have been described in mammals: extracellular signal-regulated kinase (ERK), Jun $\mathrm{N}$-terminal kinase (JNK) and p38 isoforms (1). The ERK signaling pathways are activated in response to growth factors or mitogenic signals and play a key role in cell proliferation, survival and differentiation.

Activation of ERK induces the amplification and deregulation of its nuclear transcription targets, c-myc and AP-1 $(2,3)$. It is clear that the deregulation of these pathways can lead to many other perturbations at the level of cell signaling depending on the cell type and stress signal $(4,5)$. The JNK and p38 MAPK pathways are described as stressactivated kinases, inducing inflammation and in certain cases programmed cell death. The JNK pathway is activated by cytokines, UV radiation, growth factor deprivation or DNA-damaging agents while p38 isoforms are activated by environmental stress and inflammatory cytokines (1). In response to stress stimuli, JNK as well as p38 MAPK may enhance p53 expression, p53 stabilization and consequently p53-induced apoptosis. Furthermore, it was also reported that p38 activation induces the translocation of the pro-apoptotic Bax protein from the cytoplasm to mitochondria while JNK may phosphorylate the anti-apoptotic Bcl-2 protein leading to its inactivation $(5,6)$. However, the precise regulatory mechanisms involved in the apototic effects triggered by these kinases still remain unclear.

It was shown that MAPK signaling pathways are disregulated in cancer cells altering their apoptotic response to antitumor agents. The roles played by MAPK are strongly context-dependent, influenced by cell type, nature and duration of stimuli in order to monitor apoptosis or cell survival (7). Thus, the participation of ERK, JNK or p38 in the response of tumor cells to antitumor agents is very complex, and both destructive and protective roles of each MAPK have been proposed in different systems $(5,8,9)$. It was also reported that activation of JNK or p38 often leads to the suppression of ERK activity modulating the apoptotic responses in different cancer cell lines $(10,11)$.

We reported previously that lupulone, a $\beta$-acid largely present in hops (Humulus lupulus L), is able to activate the 
extrinsic apoptotic signaling pathway through the up-regulation of p53 and of TRAIL death-receptor apoptotic pathways in TRAIL-resistant metastatic SW620 cells $(12,13)$. Here we aimed to investigate the role of ERK, JNK and p38 kinases in these events.

\section{Materials and methods}

Lupulone. Lupulone was obtained from an industrial by-product that contains high amounts of $\beta$-acids (Carlsberg Breweries A/S, Strasbourg, France) and was isolated following the procedure described previously (14).

Cell culture. SW620 cells were obtained from the European Collection of Animal Cell Culture (Salisbury, UK). They were maintained in Dulbecco's modified Eagle's medium (DMEM) containing $25 \mathrm{mM}$ glucose and supplemented with $10 \%$ heatinactivated $\left(56^{\circ} \mathrm{C}\right)$ horse serum, $100 \mathrm{U} / \mathrm{ml}$ penicillin, $100 \mu \mathrm{g} /$ $\mathrm{ml}$ streptomycin and $1 \%$ non-essential amino acids (Invitrogen Corp., Cergy Pontoise, France) and maintained at $37^{\circ} \mathrm{C}$ in a humidified atmosphere with $5 \% \mathrm{CO}_{2}$. For experiments, after trypsinization $(0.5 \%$ trypsin $/ 2.6 \mathrm{mM}$ ethylenediamine tetraacetic acid), cells were seeded at $1 \times 10^{6}$ cells in culture dishes (100 mm internal diameter). The culture medium was DMEM supplemented with $3 \%$ heat-inactivated horse serum, $100 \mathrm{U} / \mathrm{ml}$ penicillin, $100 \mu \mathrm{g} / \mathrm{ml}$ streptomycin, $5 \mu \mathrm{g} / \mathrm{ml}$ transferrin, $5 \mathrm{ng} / \mathrm{ml}$ selenium, $10 \mu \mathrm{g} / \mathrm{ml}$ insulin and $1 \%$ non-essential amino acids (Invitrogen Corp.).

Cell death analysis. SW620 cells $\left(1 \times 10^{6}\right)$ were seeded in culture dishes and pre-treated with JNK-specific inhibitor SP600125 $(10 \mu \mathrm{M})$ or ERK-specific inhibitor, SL327 or p38-specific inhibitor, SB203580 (10 $\mu \mathrm{M})$ (Sigma-Aldrich, Munich, Germany) $30 \mathrm{~min}$ before lupulone treatment $(40 \mu \mathrm{g} / \mathrm{ml})$. Cells were harvested by trypsinization at 24 and $48 \mathrm{~h}$, washed with PBS, centrifuged and fixed with $1 \mathrm{ml}$ methanol:PBS $(9: 1 \mathrm{v} / \mathrm{v})$ for $1-3 \mathrm{~h}$ at $-20^{\circ} \mathrm{C}$. Cells were washed twice in PBS and re-suspended in $200 \mu \mathrm{l}$ PBS containing $0.25 \mu \mathrm{g} / \mathrm{ml}$ RNase A and $0.1 \mathrm{mg} / \mathrm{ml}$ propidium iodide (Sigma-Aldrich). After incubation in the dark at $37^{\circ} \mathrm{C}$ for $30 \mathrm{~min}$, the fluorescence of cells $(10,000$ events) was analyzed by flow cytometry and CellQuest software (FACScan, BD Biosciences, Erembodegem, Belgium).

Analysis of $m R N A$ levels by RT-PCR. To determine expression of DR4, DR5 and p53 mRNA, extraction of total RNA and analysis by RT-PCR were performed after treatment with the p38 inhibitor SB203580 and lupulone. Total RNA was extracted using the RNeasy Mini kit (Qiagen, VWR, Copenhagen, Denmark) following the manufacturer's instructions. The HighCapacity cDNA Archive kit (Applied Biosystems, Foster City, USA) was used to reverse transcribe RNA $(1 \mu \mathrm{g})$ in $20 \mu \mathrm{l}$ of reaction mix, and measurements of the transcription levels of the selected genes were performed with TaqMan Gene Expression assays (protein p53, Hs00153349; DR4, Hs00269492; DR5, Hs00366272; Applied Biosystems). $\beta$-actin was assigned as an endogenous control (cat. no. Hs99999903; Applied Biosystems). Real-time RT-PCR was performed with TapMan Universal PCR master mix and ABI Prism 7500 Sequence Detection System (Applied Biosystems Sequence detector) in triplicate wells. The data were analyzed with a comparative threshold cycle $\left(\mathrm{C}_{\mathrm{T}}\right)$ method. This method determines the values of $\Delta$ cycle threshold $(\Delta \mathrm{Ct})$ by normalizing the average $\mathrm{Ct}$ value of each treatment with the value of each opposite endogenous control ( $\beta$-actin). Then, calculation of $2^{\Delta \Delta \mathrm{Ct}}$ of each treatment and statistical analysis were performed as described by Livak and Schmittgen (15).

Detection of p53 expression by cell flow cytometry. Cells were treated with p38 inhibitor, SB203580 $(10 \mu \mathrm{M}) 30 \mathrm{~min}$ before the treatment with lupulone $(40 \mu \mathrm{g} / \mathrm{ml})$. Cells were harvested by trypsinization at 24 and $48 \mathrm{~h}$, cell pellets were washed with phosphate-buffered saline (PBS) and fixed with a solution of PBS containing 4\% paraformaldehyde (PFA) for $1 \mathrm{~h}$ at $4^{\circ} \mathrm{C}$ in the dark. Cell pellets were washed with a solution of PBS/BSA $0.2 \%$ /Tween $0.5 \%$ and incubated with FITCconjugated mouse anti-human p53 antibody (Calbiochem; Merck Chemicals, France) or FITC-conjugated mouse IgG1 monoclonal isotype control antibody (BD Biosciences) for $1 \mathrm{~h}$ at $4^{\circ} \mathrm{C}$ in the dark. After washing with a solution of PBS/BSA $0.2 \%$ /Tween $0.5 \%$, cells were re-suspended in PBS $\left(37^{\circ} \mathrm{C}\right)$, and the fluorescence $(515 \mathrm{~nm})$ of 10,000 events per sample was analyzed by FACScan and CellQuest Software.

Expression of TRAIL receptors DR4 and DR5 after p38 inhibition. Cells were pre-treated for $30 \mathrm{~min}$ with the p38 inhibitor SB203580 at $10 \mu \mathrm{M}$ and treated with lupulone $(40 \mu \mathrm{g} / \mathrm{ml})$ at 24 and $48 \mathrm{~h}$. After trypsinization, cell pellets were washed with PBS and incubated with monoclonal mouse anti-human antibodies TRAIL-R1 (DR4) (1:100) or TRAIL-R2 (DR5) (1:100) (Alexis Biochemicals, Lausen, Switzerland) for $30 \mathrm{~min}$ at $4^{\circ} \mathrm{C}$. Cells were washed twice with PBS and incubated with FITC-conjugated goat anti-mouse IgG1 antibody (1:50) (AbD Serotec, Düsseldorf, Germany) or with FITC-conjugated mouse IgG1 monoclonal isotype control antibody (1:50) for $30 \mathrm{~min}$ at $4^{\circ} \mathrm{C}$ in the dark. After washing with PBS, cells were re-suspended in PBS, and the fluorescence of 10,000 events per sample $(515 \mathrm{~nm})$ was analyzed by FACScan and CellQuest software.

Expression of Bcl-2, Mcl-1 and Bax after p38 inhibition. SW620 cells were pre-treated for 30 min with the p38 inhbitor SB203580 at $10 \mu \mathrm{M}$ and treated with lupulone $(40 \mu \mathrm{g} / \mathrm{ml})$ for 24 and $48 \mathrm{~h}$. Cells were harvested by trypsinization and proceeded to the fixation (PBS/PFA 4\%) and permeabilization (PBS/BSA $0.2 \% /$ Tween $0.5 \%$ ) step. For Bcl-2 protein detection, cells were labelled directly with $20 \mu \mathrm{l}$ FITC-conjugated mouse antihuman Bcl-2 monoclonal antibody or FITC-conjugated mouse IgG1 monoclonal isotype control antibody for $30 \mathrm{~min}$ at $4^{\circ} \mathrm{C}$ in the dark. For Mcl-1 and Bax detection, cells were incubated with rabbit anti-human Bax polyclonal antibody or rabbit antihuman Mcl-1 polyclonal antibody (1:100) (BD Biosciences) for $30 \mathrm{~min}$ at $4^{\circ} \mathrm{C}$. After washing twice, FITC-conjugated swine anti-rabbit $\mathrm{F}\left(\mathrm{ab}^{\prime}\right) 2 / \mathrm{FITC}$ antibody was added (1:10) (Abcam, Paris, France) for $30 \mathrm{~min}$ at $4^{\circ} \mathrm{C}$ in the dark. After washing twice in permeabilization buffer, the fluorescence of 10,000 cells was analyzed using FACScan flow cytometer and CellQuest software.

Analysis of DNA fragmentation by TUNEL. After treatment, cells were harvested by trypsinization at 24 and $48 \mathrm{~h}$. Cell 


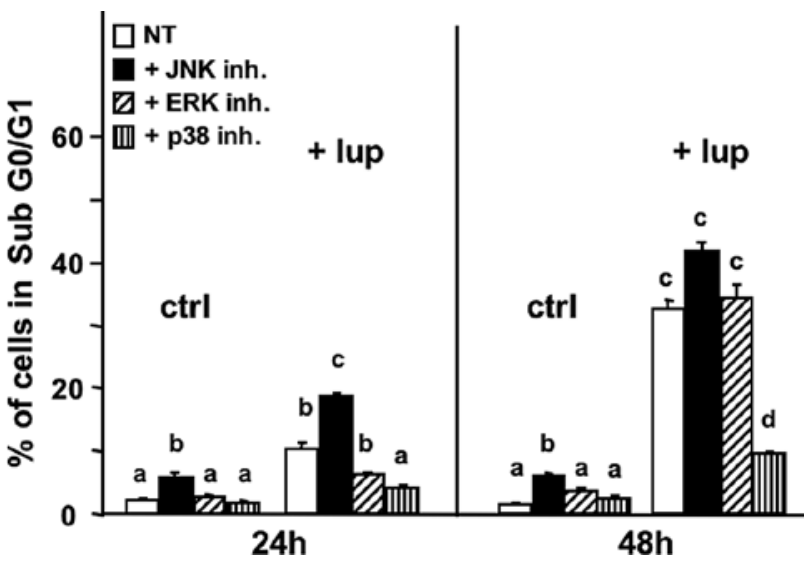

Figure 1. Analysis of lupulone-induced cell death after JNK, ERK and p38 inhibition. SW620 cells were pre-treated with each specific inhibitor, SP600125 $(10 \mu \mathrm{M})$ for JNK, SL327 $(10 \mu \mathrm{M})$ for ERK and SB203580 $(10 \mu \mathrm{M})$ for $\mathrm{p} 38,30 \mathrm{~min}$ before lupulone treatment (+lup) $(40 \mu \mathrm{g} / \mathrm{ml})$ for 24 and $48 \mathrm{~h}$. At each time point, cells were harvested, stained with propidium iodide and analyzed by flow cytometry. The percentage of hypodiploid cells present in the sub-G0/G1 region is represented as a histogram and corresponds to the mean value $\pm \mathrm{SE}$ of at least three separate experiments. For each time period, 24 or $48 \mathrm{~h}$, columns not sharing the same superscript letter differ significantly; $\mathrm{a} \neq \mathrm{b} \neq \mathrm{c} \neq \mathrm{d}, \mathrm{P}<0.05$.

pellets were washed with a solution of PBS containing $0.2 \%$ BSA and were fixed in a solution of PBS/4\% PFA for $1 \mathrm{~h}$ at $4^{\circ} \mathrm{C}$ in the dark. Cells were washed twice in PBS $/ 0.2 \%$ BSA, and pellets were permeabilized with a solution of $\mathrm{PBS} / 0.5 \%$ Tween-20/0.2\% BSA for $30 \mathrm{~min}$. After washing, cell pellets were incubated with the Mebstain Apoptosis direct kit solution (MBL, Japan) for $90 \mathrm{~min}$ at $37^{\circ} \mathrm{C}$, in the dark. This solution contained TdT buffer II, FITC-dUTP and TdT (transferase) (18:1:1). Negative control cells were incubated with a solution of TdT buffer and FITC-dUTP (19:1), and $\mathrm{H}_{2} \mathrm{O}_{2}$ was used as a positive control. Cells were washed twice, were re-suspended in PBS/0.2\% BSA and the fluorescence of the cells (10,000 events) was analyzed by flow cytometry and CellQuest software.

Statistical analysis. All data were presented as the mean \pm standard error (SE) from three independent experiments. Significant differences between the control and treated groups were evaluated by one-way ANOVA analysis, Student's t-test, or the Student-Neuman-Keuls multiple comparison test was used to determine the significance of statistical differences between data.

\section{Results}

Inhibition of MAPKs and SW620 cell survival. In order to determine the role of JNK, ERK or p38 MAPKs in lupulonetriggered SW620 cell death, the cells were treated with specific inhibitors of JNK (SP600125), ERK (SL327) and p38 (SB203580) (16-18), at a final concentration of $10 \mu \mathrm{M}$ for $30 \mathrm{~min}$ before lupulone treatment $(40 \mu \mathrm{g} / \mathrm{ml})$. The amount of dead or dying cells present in the sub-G0/G1 region was detected by flow cytometry using propidium iodide (19). A significant inhibition $(\mathrm{P}<0.01)$ of cell death was observed with the p38 inhibitor after lupulone treatment, and such an effect was not observed in the presence of JNK or ERK inhibitors

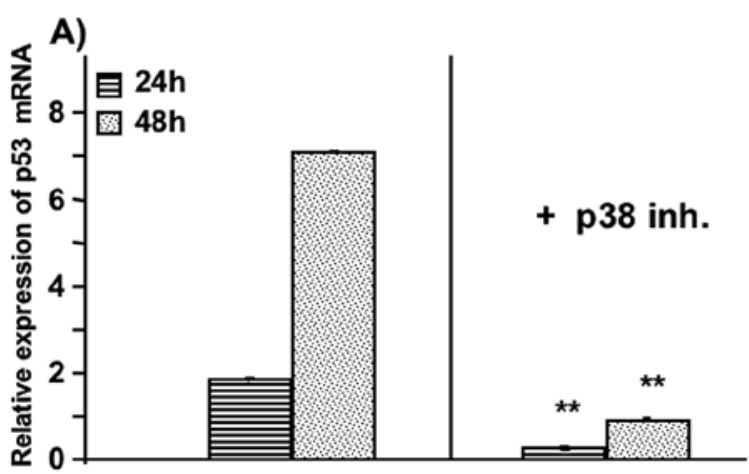

B)

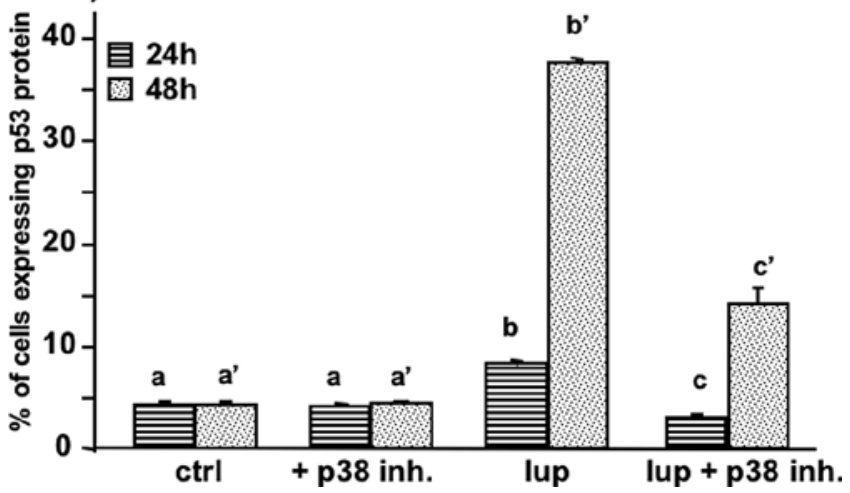

Figure 2. Expression of the p53 transcript and protein after p38 inhibition. Cells were pre-treated with the p38 inhibitor SB203580 $(10 \mu \mathrm{M}), 30 \mathrm{~min}$ before lupulone treatment (lup) $(40 \mu \mathrm{g} / \mathrm{ml})$. (A) Real-time quantitative measurement of p53 mRNA levels were represented as the fold change over untreated cells (ctrl). Data were calculated with the comparative cycle threshold method (15) and correspond to the mean value \pm SE of at least three separate experiments. For 24 or $48 \mathrm{~h},{ }^{* *} \mathrm{P}<0.001$. (B) Determination of p53 protein expression by flow cytometry. At each time point, cells were harvested and stained with FITC-conjugated anti-human p53 antibody. Increased green fluorescence was measured by flow cytometry, and data are represented by a histogram as the percentage of cells expressing p53 protein. Data correspond to the mean value $\pm \mathrm{SE}$ of at least three separate experiments. For 24 or $48 \mathrm{~h}$, columns not sharing the same superscript letter differ significantly; $a \neq b \neq c$ and $a^{\prime} \neq b^{\prime} \neq c^{\prime}, P<0.05$.

(Fig. 1). These data suggest a specific role of p38 signaling in lupulone-triggered cell death.

Up-regulation of p53 expression by p38 after lupulone treatment. In response to stress, p38 may favor apoptosis by regulating p53 protein expression $(1,20)$. In SW620 cells, p53 protein carries two mutations which appear not to affect its DNA binding ability (20). In order to determine a possible cross-talk between p38 and p53 regulation, levels of p53 transcript and protein expression were assessed using real-time PCR and flow cytometry. As shown in Fig. 2A, the amount of p53 transcripts was up-regulated after lupulone treatment in a time-dependent manner reaching a 7-fold increase at $48 \mathrm{~h}$ as compared with the untreated control cells. This effect was inhibited in the presence of the p38 inhibitor which prevented the up-regulation of p53 mRNA by lupulone (Fig. 2A). Similarly, lupulone significantly enhanced the p53 protein expression and the p38 inhibitor prevented this effect (Fig. 2B). These data demonstrate that p38 was directly involved in the activation of both $\mathrm{p} 53$ transcript and protein expression in lupulone-treated SW620 cells. 

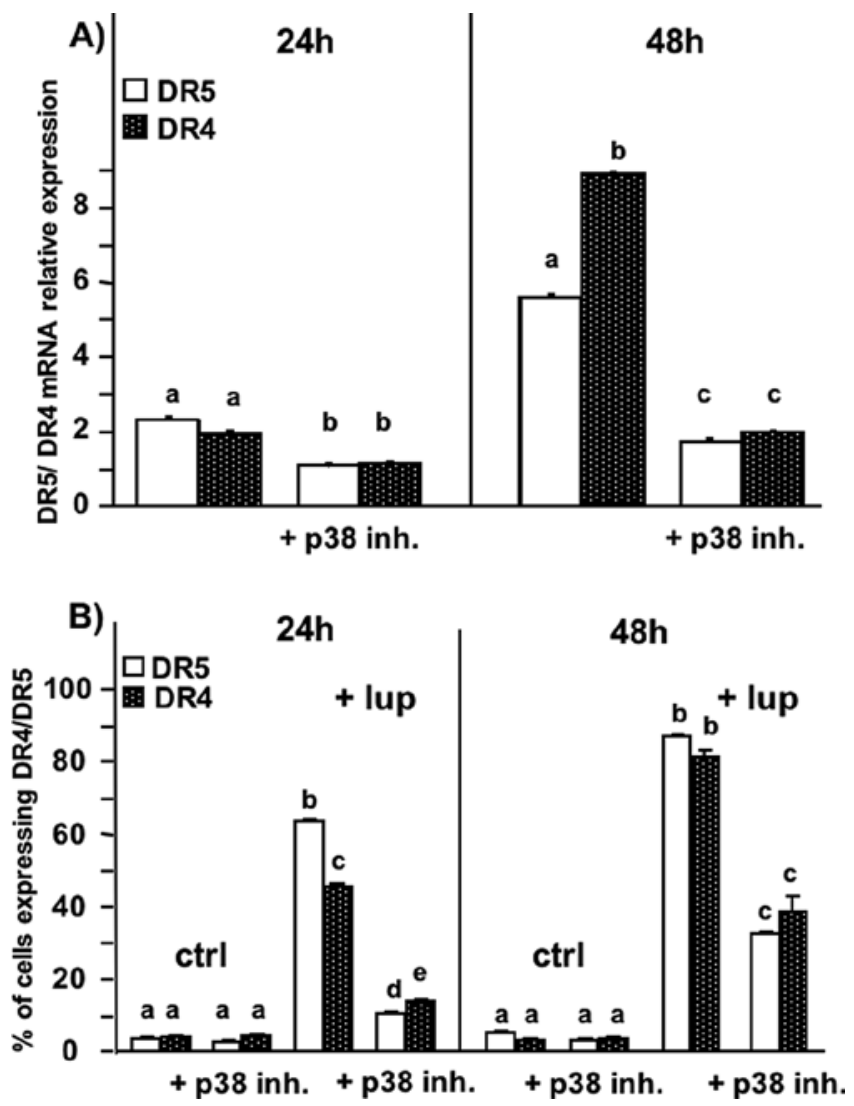

Figure 3. Analysis of TRAIL-DR4/DR5 mRNA and protein expression after p38 inhibition. Cells were pre-treated with the p38 inhibitor SB203580 $(10 \mu \mathrm{M}) 30 \mathrm{~min}$ before adding lupulone (+lup) $(40 \mu \mathrm{g} / \mathrm{ml})$ for 24 and $48 \mathrm{~h}$. (A) Real-time quantitative measurement of DR4 or DR5 mRNA levels were represented as the fold change over untreated cells. Data were calculated with the comparative cycle threshold method (15) and correspond to the mean value \pm SE of at least three separate experiments. For 24 or $48 \mathrm{~h}$, columns not sharing the same superscript letter differ significantly; $a \neq b \neq c$, $\mathrm{P}<0.001$. (B) Analysis of DR4 or DR5 protein expression by flow cytometry. At each time point, cells were harvested, stained with monoclonal antibodies against TRAIL-DR4 or -DR5 receptor and with FITC-conjugated goat antimouse IgG1 antibody. Increased green fluorescence was measured by flow cytometry, and data are represented by histograms as the percentage of cells expressing DR4 or DR5 receptors. Data are the mean value \pm SE of at least three separate experiments. At each time period $(24$ or $48 \mathrm{~h})$ columns not sharing the same superscript letter differ significantly; $\mathrm{a} \neq \mathrm{b} \neq \mathrm{c} \neq \mathrm{d} \neq \mathrm{e}, \mathrm{P}<0.05$.

Effect of p38 inhibition on TRAIL death receptors DR4/DR5. To determine the potential role of $\mathrm{p} 38$ MAPK on the activation of TRAIL death receptor expression at the cell surface observed after lupulone treatment in SW620 cells, the levels of TRAIL DR4 and DR5 mRNA and protein expression were assessed using real-time PCR and flow cytometry.

As illustrated in Fig. 3A and B, specific inhibition of p38 prevented the lupulone-triggered up-regulation of both TRAIL DR4/DR5 mRNA and protein expression. These data indicate that p38 MAPK was directly involved in the regulation of the extrinsic apoptotic TRAIL signaling pathway after lupulone treatment.

Effect of p38 inhibition on Bcl-2, Mcl-1 and Bax expression. We previously showed that in response to lupulone, SW620 cells were able to activate mechanisms favoring the protection of mitochondrial function $(12,13)$. Since it was reported that anti-apoptotic proteins of the Bcl-2 family such as Bcl-2 or

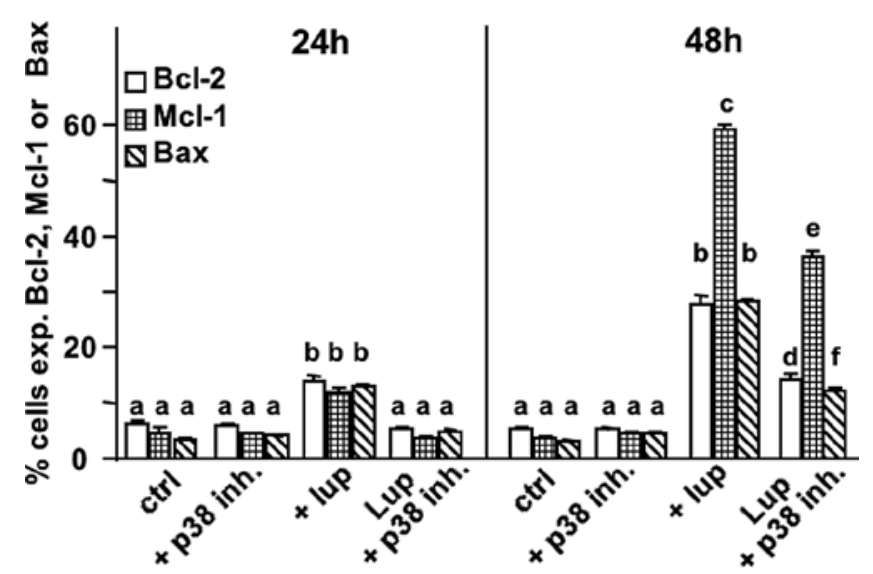

Figure 4. Effects of lupulone on Bcl-2, Mcl-1 and Bax expression after p38 inhibition. At each time point, SW620 cells were harvested, fixed and permeabilized. After washing, cells were incubated with the appropriate antibody (Materials and methods). Increased green fluorescence was measured by flow cytometry, and data are represented by histograms as the percentage of cells expressing Bcl-2, Mcl-1 or Bax proteins. Data are the mean value $\pm \mathrm{SE}$ of at least three separate experiments. At each time period ( 24 or $48 \mathrm{~h}$ ) columns not sharing the same superscript letter differ significantly; $\mathrm{a} \neq \mathrm{b} \neq \mathrm{c} \neq \mathrm{d} \neq \mathrm{e} \neq \mathrm{f}, \mathrm{P}<0.05$.

Mcl-1 are able to stabilize the mitochondrial membrane (22), we investigated whether $\mathrm{p} 38$ activation by lupulone was able to modulate the expression of these anti-apoptotic proteins. Using flow cytometry, we measured the percentage of cells expressing anti-apoptotic Bcl-2, Mcl-1 or pro-apoptotic Bax proteins after inhibition of $\mathrm{p} 38$ expression in lupulone-treated cells.

After lupulone treatment for $48 \mathrm{~h}$, both Bcl-2 and Bax expression was increased in the same proportions (Fig. 4). The number of cells expressing the anti-apoptotic protein Mcl-1 was enhanced by $60 \%$, and the Mcl-1/Bax (anti-apoptotic/ pro-apoptotic protein) ratio was equal to 2 . The inhibition of p38 function caused a 50\% reduction in lupulone-triggered activation of Mcl-1, Bcl-2 and Bax. However, the Mcl-1/Bax ratio remained unchanged (equal to 2 ) in the presence and in the absence of the p38 inhibitor.

Involvement of p38 MAPK in lupulone-triggered DNA fragmentation. We previously reported that lupulone induced the extrinsic apoptotic pathway involving the activation of the caspase- 8 and caspase- 3 cascade (12). Apoptosis is accompanied by nuclear condensation and fragmentation with extensive degradation of chromosomal DNA, these events being a biochemical hallmark of apoptosis (23). The TdT-mediated dUTP-biotin nick-end labeling (TUNEL) method which was developed by Gavrieli et al (24) is a sensitive method to visualize in situ the DNA fragmentation at the single cell level. In lupulone-treated SW620 cells for $48 \mathrm{~h}$, the inhibition of p38 function caused a $65 \%$ reduction in the number of cells with fragmented DNA (Fig. 5). These data strongly suggest that p38 may represent a major signaling pathway in the induction of apoptosis after lupulone treatment.

\section{Discussion}

The role of the MAPK signaling pathway has been reported to be important in regulating apoptosis during conditions of 


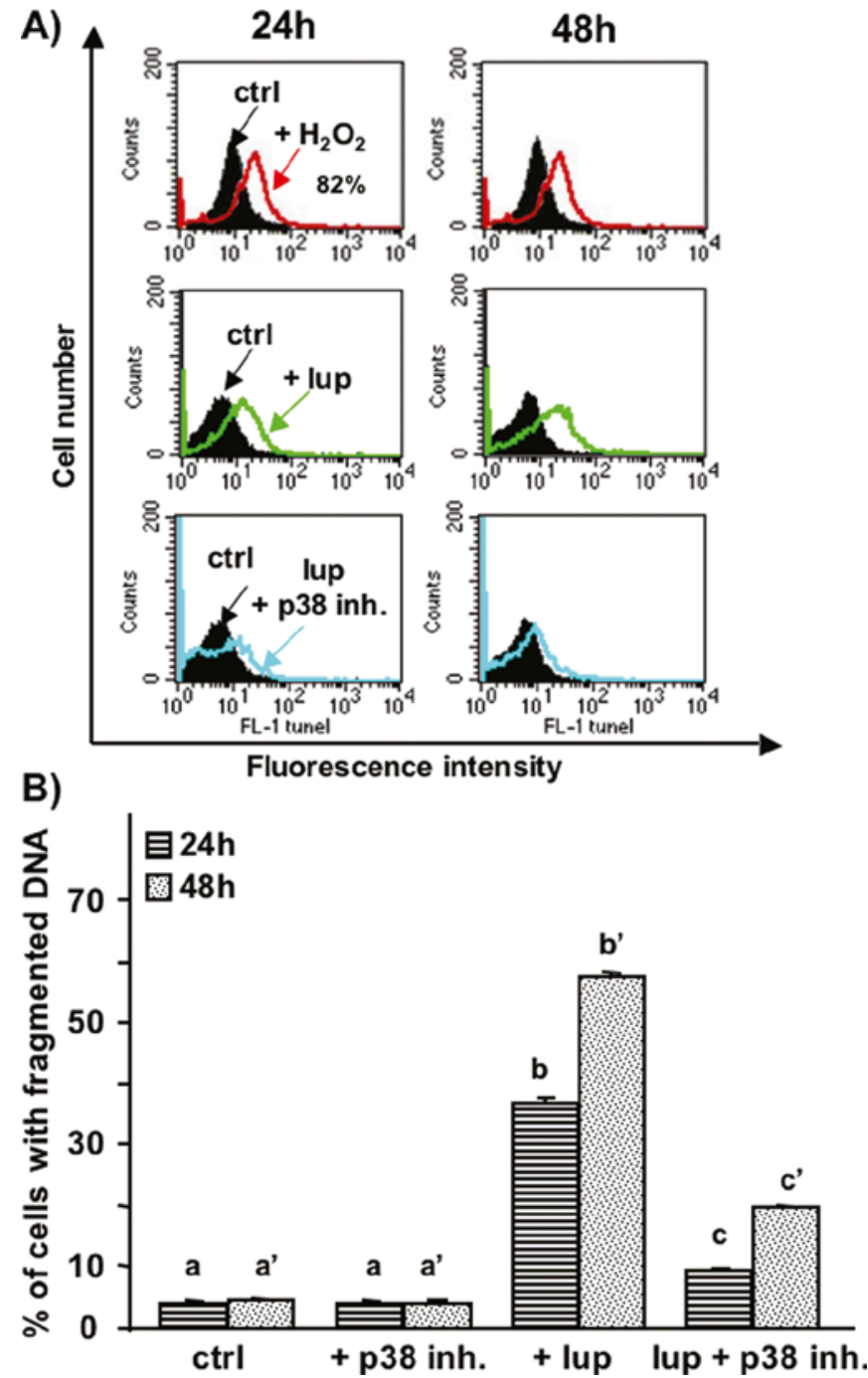

Figure 5. Effect of p38 inhibition on cellular DNA fragmentation induced by lupulone. Cells were pre-treated with p38 inhibitor, SB203580 $(10 \mu \mathrm{M})$, $30 \mathrm{~min}$ before lupulone treatment $(40 \mu \mathrm{g} / \mathrm{ml})$ for 24 and $48 \mathrm{~h}$. At each time point, cells were harvested, fixed, permeabilized and stained with the Mebstain Apoptosis direct kit solution (MBL, Japan), as described in Materials and methods, and analyzed by flow cytometry. $\mathrm{H}_{2} \mathrm{O}_{2}$ was used as a positive control. Cells with increased green fluorescence produced DNA fragmentation. (A) Data are presented as representative histogram plots and the shift on the right corresponds to cells with fragmented DNA. Negative control and control cells presented the same profile (data not shown). (B) Histogram depicts the percentage of cells with fragmented DNA. Data are the mean value $\pm \mathrm{SE}$ of at least three separate experiments. At each time period ( 24 or $48 \mathrm{~h}$ ) columns not sharing the same superscript letter differ significantly; $a \neq b \neq c$ and $a^{\prime} \neq b^{\prime} \neq c^{\prime}, P<0.05$.

cellular stress, and many studies have supported the general view that pro-apoptotic effects associated with JNK and p38 activation are counterbalanced by the activation of ERK pathway and its survival signals $(1,25)$. However, the role of MAPK is mainly context-dependent and is influenced by cell type and by the nature of stress. Both destructive and protective roles for MAPK have been proposed in different systems $(5,7)$. In the present study we demonstrated the prominent role of the p38 MAPK signaling pathway in the activation of TRAIL death receptor-mediated apoptosis by the chemopreventive agent lupulone in TRAIL-resistant metastatic SW620 cells.
We previously reported that lupulone induced apoptosis by an activation of the extrinsic pathway via TRAIL-DR4/DR5 death receptors overcoming SW620 cell resistance to TRAIL (12). Furthermore, we showed that the lupulone-triggered activation of p53 in SW620 cells plays a pro-apoptotic role through the up-regulation of TRAIL-death receptor transcripts and protein (13). However, the molecular mechanisms by which lupulone activated p53 expression and TRAIL DR4/ DR5 receptors remain unknown.

Our present data showed that when SW620 cells were exposed to lupulone in the presence of specific inhibitors of JNK, ERK or p38 MAPK, only the specific inhibition of p38 was able to prevent the apoptotic effects of lupulone in these cells. Most studies have reported that p38 MAPK pathways are involved in a variety of complex cellular responses (26). Similar to JNK, p38 may regulate apoptosis, cell cycle progression, growth and differentiation $(1,27)$. Two main MAPKK can be activated by p38: MKK3 and MKK6. Activation of MKK6 can induce p38 expression leading to promotion of caspase activity and cell death (28). Other studies have demonstrated the prominent role of p38 in the induction of Bax translocation to mitochondria leading to mitochondrial disruption and cell death $(6,29,30)$.

The transcription factor p38 is often involved in p53-regulated apoptosis and acts as a negative regulator of cell cycle progression $(31,32)$. In SW620 cells, p53 protein carries two mutations, which do not affect its ability to bind to DNA (21). In the present study we show that, in spite of these mutations, transcription and protein expression of mutated-p53 were up-regulated by p38 in lupulone-treated SW620 cells. We also showed that the activation of TRAIL-DR4/DR5 death receptors by lupulone was p38-dependent. Indeed, the specific inhibition of p38 prevented DR4 and DR5 gene transcription and related protein synthesis. Our data suggest that lupulone may overcome TRAIL resistance of SW620 cells by activating p38, which in turn up-regulates the transcription and protein expression of p53 and TRAIL-DR4/DR5 death receptors.

We previously demonstrated that lupulone activated the TRAIL-receptor apoptotic pathway (extrinsic pathway) leading to an activation of the caspase- 8 caspase- 3 cascade (12). We also reported a cross-talk between the extrinsic and mitochondrial (intrinsic) apoptotic pathways through a caspase- 8 dependent cleavage of Bid protein causing mitochondrial perturbations. However, mitochondrial function was not compromised since no release of cytochrome $\mathrm{c}$ was observed $(12,14)$. Thus mitochondrial functions remained preserved in lupulone-treated SW620 cells. In the present study we showed that lupulone induced the activation of the survival factor Mcl-1, which is a key factor in mitochondrial protection (22). The specific inhibition of the p38 pathway caused a $50 \%$ decrease in Mcl-1, Bcl-2 and Bax expression. The Mcl-1/Bax (survival/pro-apoptotic factors) ratio remained unchanged after p38 inactivation suggesting that p38 may not play a major role in the protection of mitochondrial integrity. Our data highlight the specificity of p38 in activating the extrinsic apoptotic pathway (death-receptor pathway) in metastatic SW620 cells in response to lupulone. The key role of p38 in apoptotic processes triggered by lupulone was confirmed by the observation that DNA fragmentation was prevented in these cells by the p38 inhibitor. 
In conclusion, this study provides new insights into the complex mechanisms involved in lupulone-triggered apoptosis in TRAIL-resistant SW620 cells. We showed here that the chemopreventive agent lupulone activated the p38 signaling pathway which played a major role in the up-regulation of TRAIL death receptors and of p53 expression at the genetic and protein levels. As shown previously (12), TRAIL DR4 and DR5 receptors activated caspase-8, and consequently caspase-3 leading to the observed DNA fragmentation. It has been reported that other chemopreventive compounds such as curcumin, resveratrol or quercetin induced apoptosis through an activation of JNK and p38 pathways and notably in SW620 cells after berberine treatment $(33,34)$. Our data support the view that the lupulone-triggered enhanced expression of $\mathrm{p} 38$ plays a major role by controlling p53 and the TRAIL-receptor apoptotic pathway in metastatic SW620 cells.

\section{Acknowledgements}

Virginie Lamy was supported by a fellowship provided by the Conseil Régional d'Alsace, France. The authors would like to thank Dr Behnam Taidi (Carlsberg Breweries A/S, Development Center, Strasbourg, France) for supplying the industrial by-product containing high amounts of $\beta$-acids (lupulone).

\section{References}

1. Dhillon AS, Hagan S, Rath O and Kolch W: MAP kinase signalling pathways in cancer. Oncogene 26: 3279-3290, 2007.

2. Roux PP and Blenis J: ERK and p38 MAPK-activated protein kinases: a family of proteine kinases with diverse biological functions. Microbiol Mol Biol Rev 68: 320-344, 2004.

3. Ouyang X, Jessen WJ, Al-Ahmadie H, Serio AM, Lin Y, Shih WJ, Reuter VE, Scardino PT, Shen MM, Aronow BJ, Vickers AJ, Gerald WL and Abate-Shen C: Activator protein-1 transcription factors are associated with progression and recurrence of prostate cancer. Cancer Res 68: 2132-2144, 2008.

4. Wang X, Martindale JL and Holbrook N: Requirement for ERK activation in cisplatin-induced apoptosis. J Biol Chem 275 39435-39443, 2000.

5. Fan M and Chambers TC: Role of mitogen-activated protein kinases in the response of tumor cells to chemotherapy. Drug Resist Updat 5: 253-267, 2001.

6. Kim HJ, Oh JE, Kim SW, Chun YJ and Kim MY: Ceramide induces p38 MAPK-dependent apoptosis and Bax translocation via inhibition of Akt in HL-60 cells. Cancer Lett 260: 88-95, 2008.

7. Brantley-Finley C, Lyle CS, Du L, Goodwin ME, Hall T, Szwedo D and Kaushal GP TC: The JNK, ERK and p53 pathways play distinct roles in apoptosis mediated by the antitumor agents vinblastine, doxorubicin and etoposide. Biochem Pharmacol 66: 459-469, 2003.

8. Tewari R, Sharma V, Koul N and Sen E: Involvement of miltefosine-mediated ERK activation in glioma cell apoptosis through Fas regulation. J Neurochem 107: 616-627, 2008.

9. Aesoy R, Sanchez BC, Norum JH, Lewensohn R, Viktorsson K and Linderholm B: An autocrine VEGF/VEGFR2 and p38 signalling loop confer resistance to 4-hydoxytamoxifen in MCF-7 breast cancer cells. Mol Cancer Res 6: 1630-1638, 2008.

10. Xia Z, Dickens M, Raingeaud J, Davis RJ and Greenberg ME: Opposing effects of ERK and JNK-p38 MAP kinases on apoptosis. Science 270: 1326-1331, 1995.

11. Zhang CC and Shapiro D: Activation of the p38 mitogen-activated protein kinase pathway by estrogen or by 4-hydroxytamoxifen is coupled to estrogen receptor-induced apoptosis. J Biol Chem 275: 479-486, 2000.

12. Lamy V, Roussi S, Chaabi M, Gossé F, Lobstein A and Raul F: Lupulone, a hop bitter acid, activates different death pathways involving apoptotic TRAIL-receptors, in human colon tumor cells and in their derived metastatic cells. Apoptosis 13: 1232-1242, 2008.
13. Lamy V, Bousserouel S, Gossé F, Minker C. Lobstein A and Raul F: P53 activates either survival or apoptotic signaling responses in lupulone-treated human colon adenocarcinoma cells and derived metastatic cells. Trans Oncol 5: 286-292, 2010.

14. Lamy V, Roussi S, Chaabi M, Gossé F, Schall N, Lobstein A and Raul F: Chemopreventive effects of lupulone, a hop beta-acid, on human colon cancer-derived metastatic SW620 cells and in a rat model of colon carcinogenesis. Carcinogenesis 28: 1575-1581, 2007.

15. Livak KJ and Schmittgen TD: Analysis of relative gene expression data using real-time quantitative PCR and the 2(-Delta Delta C(T)) method. Methods 25: 402-408, 2001.

16. Hu R, Kim BR, Chen C, Hebbar V and Kong AN: The roles of JNK and apoptotic signaling pathways in PEITC-mediated responses in human HT-29 colon adenocarcinoma cells. Carcinogenesis 24: 1361-1367, 2003.

17. Olson JM and Hallahan A: p38 MAP kinase: a convergence point in cancer therapy. Trends Mol Med 10: 125-129, 2004.

18. Beaulieu JM, Sotnikova TD, Gainetdinov RR and Caron MG: Paradoxical striatal cellular signalling responses to psychostimulants in hyperactive mice. J Biol Chem 281: 32072-32080, 2006.

19. Riccardi C and Nicoletti I: Analysis of apoptosis propidium iodide staining and flow cytometry. Nat Protoc 1: 1458-1461, 2006.

20. Wang H, Wang Z, Chen J and Wu J: Apoptosis induced by NO via phosphorylation of p38 MAPK that stimulates NF- $\mathrm{kB}, \mathrm{p} 53$ and caspase- 3 activation in rabbit articular chondrocytes. Cell Biol Int 31: 1027-1035, 2007.

21. Rochette PJ, Bastien N, Lavoie J, Guérin SL and Drouin R: SW480, a p53 double-mutant cell line retains proficiency for some p53 functions. J Mol Biol 352: 44-57, 2005.

22. Armstrong JS: Mitochondria: a target for cancer therapy. $\mathrm{Br} \mathbf{J}$ Pharmacol 147: 239-248, 2006.

23. Widlak P and Garrard WT: Roles of the major apoptotic nuclease-DNA fragmentation factor in biology and disease. Cell Mol Life Sci 66: 263-274, 2009.

24. Gavrieli Y, Sherman Y and Ben-Sasson SA: Identification of programmed cell death in situ via specific labelling of nuclear DNA fragmentation. J Cell Biol 119: 493-501, 1992.

25. Ballif BA and Blenis J: Molecular mechanisms mediating mammalian mitogen-activated protein kinase (MPK) kinase (MEK)-MAPK cell survival signals. Cell Growth Differ 12: 397-408, 2001.

26. Wada T and Penninger JM: Mitogen-activated protein kinases in apoptosis regulation. Oncogene 23: 2838-2849, 2004.

27. Sarkar D, Su ZZ, Lebedeva IV, Sauane M, Gopalkrishnan RV, Valerie K, Dent P and Fisher PB: Mda-7 (IL-24) mediates selective apoptosis in human melanoma cells by inducing the coordinated overexpression of the GADD family of genes by means of p38 MAPK. Proc Natl Acad Sci USA 99: 10054-10059, 2002.

28 Zarubin T and Han J: Activation and signalling of p38 MAP kinase pathway. Cell Res 15: 11-18, 2005.

29. So KS, Oh JE, Han JH, Jung HK, Lee YS, Kim SH, Chun YJ and Kim MY: Induction of apoptosis by a stilbene analog involves Bax translocation regulated by p38 MAPK and Akt. Arch Pharm Res 31: 438-444, 2008.

30. Van Laethem A, Van Kelst S, Lippens S, Declerq W, Vandenabeele P, Janssens S, Vandenheede JR, Garmyn M and Agostinis P: Activation of p38 MAPK is required for Bax translocation to mitochondria, cytochrome $\mathrm{c}$ release and apoptosis induced by UVB irradiation in human keratinocytes. FASEB J 18: 1946-1948, 2004.

31 Bulavin DV, Demidov ON, Saito S, Kauraniemi P, Phillips C, Amundson SA, Ambrosino C, Sauter G, Nebreda AR, Anderson CW, Kallioniemi A, Fornace AJ Jr and Appella E: Amplification of PPM1D in human tumors abrogates p53 tumor-suppressor activity. Nat Genet 31: 210-215, 2002.

32 Bradham C and McClay DR: P38 MAPK in development and cancer. Cell Cycle 5: 824-828, 2006.

33. Chen $\mathrm{C}$ and Kong AN: Dietary cancer-chemopreventive compounds: from signaling and gene expression to pharmacological effects. Trends Pharmacol Sci 26: 318-326, 2005.

34. Hsu WH, Hsieh YS, Kuo HC, Teng CY, Huang HI, Wang CJ, Yang SF, Liou YS and Kuo WH: Berberine induces apoptosis in SW620 human colonic carcinoma cells through generation of reactive oxygen species and activation of JNK/p38 MAPK and FasL. Arch Toxicol 81: 719-728, 2007. 